June 1995

\title{
Patients Who Request a Female Psychotherapist
}

Timothy C. Smith, MD

Thomas Jefferson University Hospital

Melinda Fudge, MD

Thomas Jefferson University Hospital

Salman Akhtar, MD

Thomas Jefferson University Hospital

Steven Samuel, PhD

Thomas Jefferson University Hospital

Follow this and additional works at: https://jdc.jefferson.edu/jeffjpsychiatry

Part of the Psychiatry Commons

Let us know how access to this document benefits you

\section{Recommended Citation}

Smith, MD, Timothy C.; Fudge, MD, Melinda; Akhtar, MD, Salman; and Samuel, PhD, Steven (1995) "Patients Who Request a Female Psychotherapist," Jefferson Journal of Psychiatry. Vol. 12 : Iss. 2 , Article 7. DOI: https://doi.org/10.29046/JJP.012.2.003

Available at: https://jdc.jefferson.edu/jeffjpsychiatry/vol12/iss2/7

This Article is brought to you for free and open access by the Jefferson Digital Commons. The Jefferson Digital Commons is a service of Thomas Jefferson University's Center for Teaching and Learning (CTL). The Commons is a showcase for Jefferson books and journals, peer-reviewed scholarly publications, unique historical collections from the University archives, and teaching tools. The Jefferson Digital Commons allows researchers and interested readers anywhere in the world to learn about and keep up to date with Jefferson scholarship. This article has been accepted for inclusion in Jefferson Journal of Psychiatry by an authorized administrator of the Jefferson Digital Commons. For more information, please contact: JeffersonDigitalCommons@jefferson.edu. 


\title{
Patients Who Request a Female Psychotherapist
}

\author{
Timothy C. Smith, M.D. \\ Melinda Fudge, M.D. \\ Salman Akhtar, M.D. \\ Steven Samuel, Ph.D.
}

\begin{abstract}
Upon arriving at an outpatient clinic, many patients request to see a female psychotherapist. Yet little has been written on this topic. The aim of this study was to explore the demographic and clinical characteristics of such patients. We compared patients who voiced a preference for a female therapist with controls on the demographic variables of age, sex, race, marital and financial status and the clinical characteristics of diagnosis, history of sexual abuse, sexual preference, overt presence of sexual or social difficulties, history of prior treatment, gender of the previous therapist, and treatment drop out rate. A chi square analysis for categorical data was used to measure differences between the two populations. We found that patients who voiced a request for a female therapist were more often white, young, or had voiced sexual or social difficulties in their chief complaint. The treatment drop out rate of study patients whose request was granted was greater than control patients who received a female therapist. The request for a female therapist may be reflective of an age or race based comfort in expressing preference, or related to specific presenting complaints in the realm of sexual or social relationships. Granting such a request without an understanding of its significance may result in premature termination of treatment.
\end{abstract}

\section{INTRODUCTION}

While much has been written about the potential effects of a therapist's gender upon the process and outcome of psychotherapy (1-6), a patient's request for a specific gender therapist has received little attention. A review of the literature revealed few papers on this topic $(7,8)$. Such inattention to a frequently encountered clinical occurrence prompted us to undertake our investigation. Our aim was to study the demographic and clinical characteristics of individuals who request a female therapist. Through this data we sought to explore the potentially significant therapeutic issues involved in treating such patients.

Timothy C. Smith, M.D. and Melinda Fudge, M.D. recently completed their residency training in Psychiatry at Thomas Jefferson University Hospital in Philadelphia, where Salman Akhtar, M.D. and Steven Samuel, Ph.D. are on the faculty. 


\section{METHODS}

This study was conducted at a resident run, university hospital outpatient psychiatric clinic. In a fifteen month period, 222 intake evaluations were performed. Thirteen male and eleven female residents worked in the clinic over the course of our study. Study subjects were selected by their having spontaneously requested a female therapist before or during intake. A control population was generated by using the next intake in which no such request was made. The two samples were then compared on the demographic variables of age, sex, race, marital and financial status and on the clinical characteristics of diagnosis, history of sexual abuse, sexual preference, overt presence of sexual or social difficulties, history of prior treatment, the gender of the previous therapist, and the drop-out rate. A chi square analysis for categorical data was used to measure differences between the two populations. Dropping out of treatment was defined as attending therapy for less than two months or seven sessions.

\section{RESULTS}

Twenty-two out of 222 new patients $(10 \%)$ requested a female therapist at the time of initial evaluation. Patients who requested a female therapist were more often younger $\left(\mathrm{p}<.06, \chi^{2}=7.61\right)$, white $\left(\mathrm{p}<.005, \chi^{2}=7.50\right)$ (Table 1$)$, and likely to voice concerns regarding sexual and/or social relationships $\left(p<.05, \chi^{2}=3.03\right)$ as their presenting complaint (Table 2). Diagnosis, sexual orientation, history of sexual abuse, socio-economic status, and marital status did not differentiate the control from the experimental group. Previous psychotherapy with either a male or female therapist was also not noted to distinguish the two groups. While seventeen of the twenty two $(77 \%)$ patients requesting a female therapist were themselves female, this percentage was not significantly different from the control group.

Fifteen of the twenty two $(68 \%)$ patients requesting a female therapist were indeed assigned to a female therapist. Two patients who voiced a preference for a female therapist later changed their minds as a result of the intake interviewer's exploring the origin of their requests. The requests of the remaining five could not be granted due to the lack of availability of female therapists; these patient did accept male therapists.

Nine of the fifteen patients $(60 \%)$ requesting and receiving female therapists dropped out of treatment prematurely. This value was significantly higher $(\mathrm{p}<.05$, $\chi=7.67$ ) than control patients receiving female therapists (Table 2).

\section{DISCUSSION}

Attempts to study patient preference of therapist gender have been inconsistent. Studies have revealed same gender preference $(1,2,9,10)$, opposite gender preference (11), preference for male therapists by both sexes (3) and preference for female therapists by both sexes (4). Methodologic differences between these studies 
TABLE 1.

Patients Requesting a Female Therapist: Demographic Characteristics

\begin{tabular}{lcc}
\hline Characteristics & Subjects & Controls \\
\hline Age & $(\mathrm{n}=22)$ & $(\mathrm{n}=22)$ \\
$<20$ & 0 & 1 \\
$20-29$ & $1^{*}$ & 4 \\
$30-39$ & 4 & 11 \\
$>40$ & 7 & 6 \\
Sex & 5 & 9 \\
Male & 17 & 13 \\
Female & 1 & 8 \\
Race & $20^{* *}$ & 14 \\
Black & 1 & 0 \\
White & 17 & 12 \\
Other & 3 & 5 \\
Marital Status & 2 & 5 \\
Single & & \\
Married/Widow & 6 & 7 \\
Separated/Divorced & 12 & 9 \\
Socioeconomic Status & 4 & 6 \\
Medical Assistance & & \\
Hospital Subsidy & & \\
Private Pay &
\end{tabular}

$* \mathrm{p}<.06 ; * * \mathrm{p}<.005$

further complicate their interpretation. A more important discrepancy to our purpose is the fact that these studies refer to patients already engaged in treatment. Our investigation, in contrast, deals with the patient's request for a female therapist before or during the initial evaluation.

In comparing such patients with controls (Tables 1 and 2), we found four positive findings. First, the explicitly stated preference of younger patients in our sample may reflect a consumer-oriented mentality in which asking for what one wants is valued. Second, a similar reasoning may apply to the race-related differences in our study. White patients in our sample may have a greater sense of empowerment than black patients. An important consideration is that black patients were in the minority, both in the patient sample and the clinic staff. Our third and fourth findings confirm our intuitive prediction, that patients requesting a female therapist voice concerns with sexual or social relationships. This finding may be due to the widespread belief that women are more sensitive and gentle then men (12) and hence less threatening when patients reveal such concerns.

We were surprised by our negative findings. We had expected more female patients, especially those who has been sexually abused, to have requested a female therapist. Our hypothesis was based upon clinical impressions and the feminist perspective of a female to female therapist-patient dyad being preferable (3). Clearly, neither belief was borne out by the data. 
TABLE 2.

Patients Requesting a Female Therapist: Clinical Characteristics

\begin{tabular}{lcc}
\hline Characteristics & Subjects & Controls \\
\hline Diagnosis & 1 & 4 \\
Schizophrenia & 11 & 13 \\
Affective Disorder/Depr. & 4 & 3 \\
Affective Disorder/Manic & 10 & 7 \\
Anxiety Disorder & 2 & 1 \\
Organic Disorder & 8 & 7 \\
Adjustment Disorder & 14 & 10 \\
Personality Disorder & & \\
History of Sexual Abuse & 4 & 3 \\
Yes & 18 & 19 \\
No & 16 & 18 \\
Sexual Preference & 5 & 3 \\
Heterosexual & 1 & 1 \\
Homosexual & & 3 \\
Bisexual & $8^{*}$ & 19 \\
Sexual/Social Chief Complaints & 14 & 3 \\
Yes & & 3 \\
No & 3 & 4 \\
History of Prior Treatment & 9 & 10 \\
By Male \& Female & 2 & 2 \\
By Female & 6 & 8 \\
By Male & 2 & 2 \\
No Prior Treatment & 11 & 6 \\
Not Obtained at Intake & $9 *$ & \\
Drop Out Rate & 2 & \\
Total Number of Drop Outs & & \\
Assigned to Female & & \\
Assigned to Male & & \\
$\quad$ No & & \\
\hline
\end{tabular}

$* \mathrm{p}<.05$

Our drop out rate data, while reflective of a relatively small sample, reveals interesting findings. The high drop out rate (41\%) of female study patients whose request was granted may, at first glance, be surprising. A patient's request at the onset of treatment may be a harbinger of future requests which at some point will not be able to be granted.

In light of the positive and negative findings of our study, it seems that the request for a female therapist is either reflective of an age and/or race based comfort in expressing preference and/or specific presenting complaints in the realm of sexual or social relationships. These findings dictate that each request be explored on an individual basis. Merely granting the request does not necessarily imply that treatment will be more likely to be successful or longer-lasting. The interviewer must inquire as to why the patient has made such a request or risk incorrect assumptions about its origin, thus colluding with factors which might have led to such a request. The importance of exploring the patient's request for a specific gender therapist is 
underscored by the literature of the past thirty years which has focused on what gender therapist should treat a particular gender patient rather than addressing the significance of a patient having made such a choice. We expect that such a choice presents an opportunity to examine how the patient perceives the therapeutic community into which he or she is about to enter.

The decision to grant a patient's request for a female therapist rests upon the tension between adding to a resistance to therapy versus fostering a comfortable treatment relationship. In several of the cases where a patient was able to explore the nature of their request for a female therapist, irrational beliefs towards males were unbelieved and indeed the patients were able to continue working with a male therapist. Such cases lend support to the adage that a patient's choice of therapist may complicate the treatment, but need not prevent optimal outcome.

Clearly our findings and their interpretations are tentative. Further study needs to be done to assess the importance of a patient's initial request for a specific gender therapist. Just as we found surprising results in our preliminary study, long term follow up may reveal unsuspected effects on outcome, drop out rates, and satisfaction with care.

\section{REFERENCES}

1. Mogul KM: Overview: The Sex of the therapist. American Journal of Psychiatry 1982; 139:1-12

2. Jones EE: Impact of client and therapist gender on psychotherapy process and outcome. Journal of Consulting and Clinical Psychology 1982; 50:259-272

3. Chesler P: Women as psychiatric and psychotherapeutic patients. Journal of Marriage and the Family 1971; 33:746-759

4. Engleman EG: Attitudes toward women physicians: a study of 500 clinic patients. Western Journal of Medicine 1974; 120:95-100

5. Kirshner L, Genack A: Effects of gender on short-term psychotherapy: Theory, Research \& Practice 1978; 15:158-167

6. Thompson C: Notes on the psychoanalytical significance of the choice of analyst. Psychiatry 1938; 1:205-216

7. Thorne S: Women show growing preferences for treatment by female physicians. Can Med Assoc J 1994; 150:1466-7

8. Van Den Brink-Muinen A, de Bakker DH: Consultations for women's health problem's: Factors influencing women's choice of sex of general practioner. Br. J General Practice 1994; 44:205-10

9. Kris KB, Silberger J: Medical students gender preference when selecting a psychiatrist. Journal of American College Health 1986; 35:5-10

10. Levinson RM, McCoullum KT: Gender homophily in preferences for physicians. Sex-Roles 1984; 10:315-325

11. Person ES: Women in therapy: Therapist gender as a variable. Internatinal Review of Psychoanalysis 1983; 10:193-204

12. Holt RR, Luborsky L: Personality patterns of psychiatrists: a study of methods of selecting residents. N.Y.: Basic Books; 1958 